\title{
Can the Medical-nursing Combined Care Promote the Accessibility of Health Services for the Elderly in Nursing Home? A Study Protocol of Analysis of the Effectiveness Regarding Health Service Utilization, Health Status and Satisfaction with Care
}

\author{
J Bao, X-J Wang, Y Yang, R-Q Dong, Z-F Mao
}

\begin{abstract}
Background: Currently, segmentation of healthcare and daily care for the elderly living in nursing homes usually results in the elderly not getting medical treatment timely and effectively. The medical-nursing combined care, which has been put into practice in several areas in China, is developed to enhance the accessibility of healthcare for the elderly. The aim of the study is to explore the effectiveness of the new care service, based on Andersen model, regarding health service utilization, health status and service satisfaction.

Methods: The effectiveness of medical-nursing combined care will be measured in a cross-sectional study in nine nursing homes in Jianghan District, Wuhan, China, with 1067 old residents expected to participate. The questionnaire containing items of demographics, health service use, service satisfaction and instrument of SF-36 V2 is developed based on the conceptual framework of Andersen behaviour model of health service utilization. Descriptive analysis, variance analysis, multiple factors analysis, and correlation analysis will be performed to compare the sociological characteristics, health service use, health status and service satisfaction of the elderly living in different modes of nursing homes, to explore the influence factors of care effectiveness, as well as to study the relationship between health behaviour and health outcomes.

Conclusion: The study design of analysing the effects of medical-nursing combined care and performing the horizontal comparison among the nursing homes under the framework of Andersen model is blazing new trails. Recruitment and design of questionnaire are important issues. Successful data collection and quality control are also necessary. Taking these into account, this study is estimated to provide evidence for the effectiveness of medical-nursing combined care service in China.
\end{abstract}

Keywords: Andersen model, health service utilization, medical-nursing combined care, older people

\section{¿Puede la Combinación de la Atención Médica y los Cuidados de Enfermería Promo- ver la Accesibilidad de los Servicios de Salud para las Personas Mayores en los Hogares de Ancianos? Un Protocolo de Estudio del Análisis de la Efectividad con Respecto a la Utilización de Servicios de Salud, Estado de Salud y Satisfacción con el Cuidado}

J Bao, X-J Wang, Y Yang, R-Q Dong, Z-F Mao

\begin{abstract}
RESUMEN
Antecedentes: Actualmente, la segmentación de la atención a la salud y el cuidado diario de las personas mayores que viven en hogares de ancianos, trae generalmente como resultado que los ancianos no reciben tratamiento médico oportuno y eficaz. La combinación de la atención médica y los cuidados de enfermería, que se ha puesto en práctica en varias áreas en China, tiene por objeto mejorar la accesibilidad de la atención a la salud para los ancianos. El objetivo del estudio es explorar la eficacia del
\end{abstract}

From: Global Health Institute, Wuhan University, 115 Donghu Road, Wuchang District, Wuhan 430073, China.
Correspondence: Professor Z-F Mao, Global Health Institute, Wuhan University, 115 Donghu Road, Wuchang District, Wuhan 430073, China. E-mail: baojiewuhan@126.com 
nuevo servicio de atención, basado en el modelo de Andersen sobre la utilización de servicios de salud, estado de salud, y satisfacción del servicio.

Métodos: La efectividad de la combinación de los cuidados médicos y de enfermería se medirá en un estudio transversal en nueve hogares de ancianos del Distrito de Jianghan, Wuhan, China, en el que se espera que participen 1067 residentes de edad avanzada. El cuestionario que contiene aspectos de demografía, uso de los servicios de salud, satisfacción con los servicios, y el instrumento SF-36 V2, se desarrolla a partir del marco conceptual del modelo conductual de Andersen sobre la utilización de los servicios de salud. Se realizarán análisis descriptivos, análisis de varianza, análisis de factores múltiples, y análisis de correlación, con el propósito de comparar las características sociológicas, el uso del servicio de salud, la satisfacción con el servicio, y el estado de salud de los ancianos que viven en distintas modalidades de hogares de ancianos. Esto permitirá explorar los factores de influencia de la eficacia de la atención, así como estudiar la relación entre el comportamiento de la salud y los resultados de salud.

Conclusión: El diseño del estudio de análisis de los efectos de la combinación de los cuidados médicos $y$ de enfermería, y la comparación horizontal entre los hogares de ancianos en el marco del modelo de Andersen, está abriendo nuevos caminos. El reclutamiento de los participantes y el diseño del cuestionario son cuestiones importantes. La exitosa recolección de datos y el control de la calidad son también necesarios. Tomando en cuenta lo anterior, se estima que este estudio proporcione evidencia sobre la efectividad del servicio combinado de atención médica y cuidados de enfermería en China.

Palabras claves: Modelo Andersen, utilización de servicios de salud, combinación de la atención médica y los cuidados de enfermería, personas mayores

West Indian Med J 2015; 64 (5): 515

\section{INTRODUCTION}

With the extension of human life span and the decline of birth rate, China is rapidly becoming an ageing society, and this will have repercussions for society. In $2014,15.5 \%$ of the Chinese population (212 million) was 60 years or older (1). The elderly, whose advanced age is associated with diseases, physical dysfunction and psychological problems, will seriously challenge the Chinese old-age security system and healthcare system. Their care needs are complex, multivariate, time-consuming and continuous (2). Moreover, along with the implementation of the policy of family planning, as well as the transformation of society and economy, the change in family structure weakens the function of the family providing for the aged. In this case, the elderly increase the demand for professional pension institutions and community services, as well as varying degrees of demand on daily life care and healthcare services (3).

In China, most medical institutions only provide elderly patients with outpatient and short-term inpatient services when they are seriously ill, while the number of geriatric specialists in hospitals and clinics is few. At the same time, most nursing homes can only provide general daily care. Even if some institutions are in a good condition and are equipped with simple medical facilities, they may not have professional quality medical management, nor can they satisfy the increasing medical service demand of the elderly $(4,5)$. The segmentation of organizations and fragmentation of care service tend to negatively affect the provision of long-term care as well as support for chronic diseases and for the elderly who demand complex care needs, which will probably lead to the problem of the elderly not getting timely and effective medical treatment (6). It is a common phenomenon in China that the aged have to go to several places, including homes, hospitals and nursing homes, until they can ultimately receive treatment. Under such circumstances, the elderly usually spend a great amount of money on additional medical services, thus resulting in a heavy burden on their families (7).

However, as a solution to control these healthcare challenges, a new approach of combining medical care with daily care in nursing institutions for the elderly residents has received a great deal of attention. In 2013, the Chinese government adopted the proposal of combining medical and healthcare with the elderly service for the first time. It is committed to strengthen the accessibility and priority of health service for the elderly, meet the medical demand in the process of nursing institution services and raise the overall level of the endowment $(8,9)$. This new concept not only includes traditional daily care and mental psychological services but also includes health promotion, medical rehabilitation care services, disease diagnosis, medical treatment, health counselling, hospice care and other basic medical care. Therefore, it reflects the concept of constant care for the elderly and the three interrelated phases including disease prevention, disease treatment and disease rehabilitation $(4,5,10)$. Moreover, it is not only integration in the form of organization and service, but also the integration of medical resources and daily nursing resources, which emphasizes the service linkage between relevant government departments and highlights the mechanism innovation in management of endowment service (11-13). 
Modes of medical-nursing combined care service

Since 2013, the pilot work of medical-nursing combined care for the elderly has been put into practice at several places in China $(4,5,14,15)$. According to whether the cooperation between medical institutions and nursing homes involved the adjustment of property right, the types of pilot work can be mainly divided into two classes, called Tight Mode and Loose Mode $(16,17)$.

The Tight Mode, which can be further divided into two kinds, mainly refers to the mode of the corporation of the medical institution and nursing home being the same, owing to the cooperation between these two organizations $(16,17)$. The first kind is that a nursing home founds a medical institution, such as a senior apartment which provides more than 800 beds for the aged in Jianghan District, Wuhan. And after the permission by the District Health Board in 2010, the clinic in this institution was transformed into a hospital especially for the elderly and it added beds for geriatric rehabilitation, so that the elderly who have common diseases need not go to see a doctor outside the institution. The second kind is that the medical institution runs a nursing home based on its medical resources. Since 2000 , the community health services institutions have been trying to start medical rehabilitation services for the elderly and accepting the elderly who are incapable of movement or need long-term care in Jianghan District, Wuhan. By the end of 2014, there were three primary healthcare institutions that had, in total, set up 166 pension rehabilitation beds and accepted more than 6400 elderly to stay.

The Loose Mode mainly refers to the mode of nursing homes and medical institutions cooperating on services by signing a contract, which does not involve the adjustment of property rights, and these two institutions still belong to different corporations $(16,17)$. With Yongkang and Shumei senior apartments for the elderly, for example, these are two representative private pension services institutions. After coordination between Jianghan District Health Planning and District Civil Affairs Bureau, two community health centres facilitated medical services at the two private pension institutions for the elderly, including health examinations, diagnosis and injections, emergency treatments and other basic medical services as well as organizing the team of general practitioners to sign the "Medical Support Services Agreement Binding".

Since the medical-nursing combined care service aims to increase the accessibility and conveniences of medical services for the elderly living in nursing homes, whether each mode enhances the utilization level of medical and health services, and further leads to the positive effects on long-term care for the elderly is the key question that this study is trying to answer.

\section{Conceptual model: Andersen's behaviour model of health service utilization}

Andersen's behavioural model of health service use, which was initially developed in the 1970s, consists of health services use, including environment, population characteristics, health be- haviour and outcomes in four sectors. It portrays the multiple influence factors on health service use, health status and service satisfaction (18-21). The aim of Andersen model is to reflect on the accessibility of health services and the resultant health outcomes, which has similar consideration when analysing the effectiveness of medical-nursing combined care for the elderly. Therefore, the Andersen model is used as the theoretical framework of this study, and the Figure displays the conceptual model under the medical-nursing combined care delivery. It assumes that the elderly living in institutions of different care modes, with diverse sociological features, will have varied levels of health service utilization and varied health status and further service satisfaction.

This article describes the study design of the evaluation of the effects of the medical-nursing combined care on the elderly in the nursing home based on Andersen model, and is funded by the health and family planning commission of Hubei province (project number WJ2015GB012).

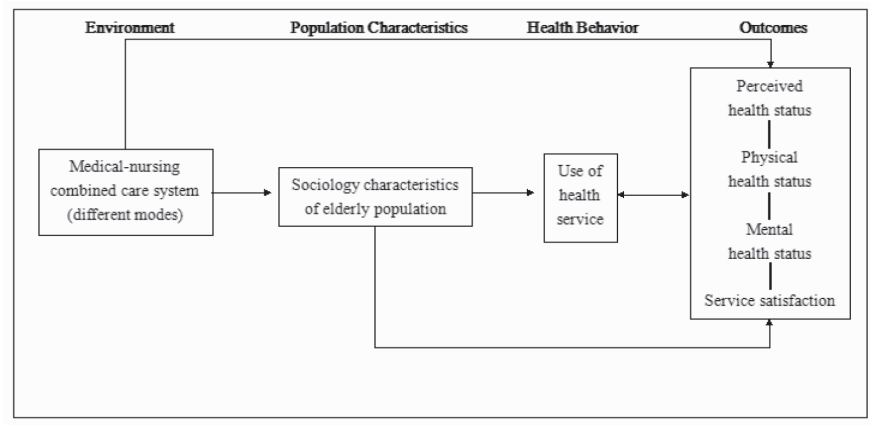

Figure: The conceptual framework of health service utilization in this study.

\section{METHODS AND DESIGN}

\section{Aim}

The aim of the project is to evaluate whether the medical-nursing combined care promotes the accessibility of health services for the elderly in nursing homes, and improves the health status and further satisfaction with care. It seeks to accomplish this with questionnaires and statistical analysis. The research questions for the evaluation study are as follows: What is the effectiveness of each medical-nursing combined care mode on the elderly living in nursing homes regarding health service utilization, health status and satisfaction with care? What are the differences and the factors affecting long-term care in all modes? What is the correlation among health service use, health status and service satisfaction for the elderly?

\section{Design and setting}

The design of the study is cross-sectional, comprising the elderly living in nursing homes. Living in nursing homes is defined as living in various types of endowment institutions, including Tight Mode, Loose Mode and non-pilot institutions. And the horizontal comparison of effectiveness is being conducted. Recruitment is estimated to be performed in a total of 13 endowment institutions in Jianghan district, Wuhan. 


\section{Study sample: sampling and eligibility criteria}

This study intends to adopt the random stratified cluster sampling to select the elderly living in nursing homes as the participants of the questionnaire survey. According to the formula of simple random sampling, under the $95 \%$ confidence level and $5 \%$ sampling error, considering the response rate and effect of design, the sample size of this study is considered not less than 1067 persons.

As of December 2014, there are 13 endowment institutions with a total of 1845 beds in Jianghan district, Wuhan. The occupancy rate of each institution is more than 90 per cent. Collecting and comparing the data of health services utilization among the elderly over the past one year scientifically requires that the duration of each institution in its own mode, by June 30,2015 - before the survey - be longer than one year. All of the 13 nursing homes meet this requirement. Since the percentage of bed size in the three types of institutions is $59 \%$, $31 \%$ and $10 \%$, respectively, this study plans to choose three institutions of Tight Mode, three nursing homes of Loose Mode, and three non-pilot institutions as the survey sites according to the bed size of each institution. The information on these nursing homes is shown in the Table.

Table: Information on nursing homes to be selected in this study

\begin{tabular}{|c|c|c|c|}
\hline Name of nursing home & Practices & Mode & Bed size \\
\hline $\begin{array}{l}\text { Jianghan District Senior } \\
\text { Apartment }\end{array}$ & $\begin{array}{l}\text { A nursing home } \\
\text { founded by a } \\
\text { medical institution }\end{array}$ & Tight Mode & 800 \\
\hline $\begin{array}{l}\text { Changqing Street Nursing } \\
\text { Home }\end{array}$ & $\begin{array}{l}\text { A medical } \\
\text { institution-run } \\
\text { nursing home }\end{array}$ & & 50 \\
\hline $\begin{array}{l}\text { Minquan Street Nursing } \\
\text { Home } \\
\text { Yongkang Senior Apartment } \\
\text { Shumei Senior Apartment } \\
\text { HBM Pension Centre }\end{array}$ & $\begin{array}{l}\text { Nursing homes and } \\
\text { medical institutions } \\
\text { that cooperate by } \\
\text { signing a contract }\end{array}$ & Loose Mode & $\begin{array}{r}80 \\
130 \\
147 \\
120\end{array}$ \\
\hline $\begin{array}{l}\text { Jianqiao Senior Apartment } \\
\text { Yangchahu Senior } \\
\text { Apartment } \\
\text { Tangjiadun Street Senior } \\
\text { Apartment }\end{array}$ & $\begin{array}{l}\text { A part-time doctor is } \\
\text { hired in a private clinic }\end{array}$ & $\begin{array}{l}\text { Non-pilot } \\
\text { institution }\end{array}$ & $\begin{array}{l}65 \\
60\end{array}$ \\
\hline
\end{tabular}

This questionnaire survey will screen for two inclusive criteria in the elderly aged 60 years or older living in the nine nursing homes: i) be conscious, be able to read or verbally expressive, no communication barriers with investigators and ii) willing to respond after understanding the study purpose. Severe mental disorders, cognitive disorders or terminally ill old people are excluded.

\section{Ethical consideration}

The cross-sectional survey in nursing homes is approved by the Ethics Committee Institutional Review Board of Wuhan
University and registered in the health and family planning commission of Hubei province (WJ2015GB012).

\section{Data collection and instruments}

Demographics: Data on sociological characteristics of the elderly in the nursing home, including age, gender, education, marital status, monthly income, and social insurance status (22-25), will be collected.

Health service utilization: Research has shown that the use of health service for the frail elderly can be evaluated from inpatient admission, outpatient visits and emergency admission (22-28). Thus, two-week morbidity rates, times of two-week outpatient visits, times of one-year inpatient admission and times of one-year emergency admission will be measured in this study. Besides, considering medical-nursing combined care service includes the connotation of health promotion and rehabilitation nursing, one-year use rates of disease prevention and of disease rehabilitation will also be selected regarding health service utilization of the aged. The information investigated from the elderly will be checked by means of health records in the nursing home.

Perceived health status: Version 2 of the SF-36 health survey, which contains nine dimensions, is capable of measuring the physical and mental health status of the elderly $(24,28,29)$; item 1 regarding general health perceptions, item 2 regarding changes of health status in the past one year and item 11 regarding perceived current health status will be used.

Physical health status: Four dimensions of the SF-36 V2, including physical functioning, role of physical and social functioning, and bodily pain, will be used to measure the physical health of the elderly in nursing homes. Questions come from items 3, 4, 6, 7 and 8 in the SF-36 instrument.

Mental health status: Three dimensions of the SF-36 V2, including mental well-being, role of emotion, and vitality/energy, will be used to measure the psychological health of the elderly in nursing homes. Questions come from items 5, 9 and 10 in the SF-36 instrument.

Service satisfaction: A questionnaire developed for the study on care service satisfaction is composed of dimensions including general satisfaction, accessibility and convenience, hardware facilities, software service and service price. Each item is scored on four levels: excellent, good, fair and poor (27-33).

\section{Data analysis}

The data will be analysed using SPSS version 17.0. Descriptive analysis is mainly used to show the basic demographic information, health service use, health status and service satisfaction of the elderly in nursing homes.

To compare the health behaviour and health outcome of the elderly living in different modes of nursing homes or in different demographic characteristics, similarity of characteristics among the tight mode institutions, loose mode institutions and non-pilot institutions will be assessed with 
Chi-square tests, $t$-tests or other methods of variance analysis. To explore the influence factors of health behaviour and health outcomes of the elderly in nursing homes, multiple factor analysis of the impact of institution type on health services utilization, health status and service satisfaction, and multiple factor analysis of health service utilization, health status and service satisfaction of the elderly in each mode will be performed.

To study the relationship of health service use and general health level, and the relationship of health service use and general service satisfaction, Pearson correlation, canonical correlation (including standardized coefficient, load coefficient and percentage of normalized variance explained by typical variable) will be analysed.

\section{DISCUSSION}

\section{Design}

To our knowledge, few studies have investigated the effect of medical-nursing combined care service on the elderly in nursing homes, and we found no studies in which the effectiveness among the modes of combined care was contrasted (34-37). In this respect, this cross-sectional study of analysing the effects of medical-nursing combined care and performing the horizontal comparison of the effectiveness among the nursing homes is unique.

To explore the effectiveness of medical-nursing combined care, Andersen's behaviour model of health service utilization was applied to guide the framework of this empirical research $(21,22,38)$. It assumed that the elderly living in the nursing homes of differential pilot modes will be at diverse levels of health care utilization, health status and satisfaction. Meanwhile, the aged residents living in the pilot institutions of medical-nursing combined care will get better accessibility to health services utilization, higher health status and more service satisfaction than the elderly in non-pilot institutions.

A few limitations should be mentioned as well. First, the cross-sectional survey may be too short a duration to demonstrate the effectiveness of the new care model. Compared with the follow-up study, this study reflects the different levels and characteristics of care effects on the elderly in a short time, rather than the objective change of care effect $(23,39-43)$. Therefore, it is difficult to observe the continuous process in development of health service accessibility and health outcome, and to catch the key point of improvement from this study. However, because the new care model is an already existing institutional arrangement led by government, a followup study is difficult to carry out. In addition, for collecting the information of health service use scientifically, the eligibility criteria of old residents living in the nursing home longer than one year will be required, which may result in the loss of sample size. Furthermore, due to the differences in both the duration of each nursing home being in the pilot mode and the period of every aged residents living in the nursing home, this study has to deal with potential design bias of effectiveness assessment.

\section{Questionnaire}

Medical-nursing combined care service for the elderly is still in the primary stage of development in China, therefore, there is no related assessment questionnaire of care effectiveness for reference. It can be regarded as a challenge for the present study. Based on the framework of Andersen model, commonly used indicators/items of health service use and service satisfaction, as well as a classic questionnaire of health status will be selected to evaluate the effectiveness of medical-nursing combined care. Methods of brainstorming and Delphi will be used to modify and improve the questionnaire, and the inspection of reliability and validity will be performed as well.

\section{Data collection and quality control}

Graduate students in the study group will be selected as investigators and will be trained before the survey. The completed questionnaires will be reviewed and be given unified numbers. For easy data input and statistical analysis, each item in the questionnaire will be coded as well. EpiData software will be used to create the database and collect the data information.

The following measures will be taken to control the quality of study data:

- Pretest will be conducted in one nursing home before the formal survey. Although each important indicator in the questionnaire has clear definition and criteria for respondents to understand the content accurately, items in the questionnaire and implementation plan of the survey will be modified according to the problems identified in the pretest.

- Graduate students in this research group will get strict training to understand the purpose of this study, the content of the questionnaire and the survey methods. A supervisor will be selected in each institution to review the completed questionnaires simultaneously.

- Five per cent of the questionnaires will be sampled randomly, and questionnaires will be sent back to investigators to supplement and correct further when missing items or filling mistakes are found. Information on healthcare utilization of the elderly will be checked with the health records in the nursing homes as well.

- Data check will be carried out after the data entry to avoid input mistakes.

\section{Study status}

Data collection will start in July 2015 and follow-up data analysis will end in September 2015. The result of this study will be expected in December 2015.

\section{CONCLUSION}

In conclusion, we have designed a cross-sectional study to evaluate the effectiveness of medical-nursing combined care regarding health service use, health status and service satis- 
faction in a population of elderly living in nursing homes. We hope to demonstrate that the medical-nursing combined care service, which will be regarded as a solution to the challenges current long-term care systems are facing, could increase the accessibility and conveniences of medical services and further improve the health outcome for the elderly.

\section{REFERENCES}

1. National Bureau of Statistical of the People's Republic of China. China Statistical Yearbook; 2015 Feb 26. Available from: http://www. stats.gov.cn/tjsj/zxfb/201502/t20150226_685799.html

2. Leichsenring K. Developing integrated health and social care services for older persons in Europe. Int J Integr Care 2004, 10: 1-13.

3. The State Council. Plan of Social Service System for the aged (20112015). State Council; 2011 Dec 28. Available from: http://www. china.com.cn/policy/txt/2011-12/28/content_24266535.htm

4. Wang SY, Zhang ZS, Sun WC. Modes and pathway of medical-nursing combined care service report of promoting the integration of health service and daily care. China Social Welfare 2013; 12: 11-4.

5. Liu H. The reflection and suggestion about promotion of "medical support integration" in Shanghai. J Sci Dev 2014, 5: 97-106.

6. Alaszewsiki A, Billings JR, Coxon K. Integrated health and social care for older persons: theoretical and conceptual issues. Canterbury, Kent: University of Kent, Center for Health Services Studies; 2003: 3-29. Available from: https://kar.kent.ac.uk/5440/

7. Mi H, Yuan XH. The internal and external problem of medical-nursing combined care institutions. China Labor and Social Security News; 2013 Dec 20. $3^{\text {rd }}$ ed.

8. The State Council. A number of points on promoting the development of pension service for the aged. State Council; 2013 Dec 13. Available from: http://www.gov.cn/zwgk/2013-09/13/content 2487704.htm

9. The State Council. A number of points on promoting the development of health service. State Council; 2013 Oct 14. Available from: http://www. gov.cn/Zwgk/2013-10/14/content_2506399.htm

10. Ji J, Wang GL. Research on the novel models of medical-nursing combined pension institution from the perspective of collaboration. Chinese J Soc Med 2014; 31: 376-7.

11. Sheying C. Historical and global perspectives on social policy and "aging in community". Aging Int 2011; 37: 1-15.

12. Kushel M. Older homeless adults: can we do more? J Gen Intern Med 2011; 27: 5-6.

13. Scharlach A. Creating aging-friendly communities in the United States. Aging Int 2011; 37: 25-38.

14. Liu QF, Sun RL. A preliminary study on the medical-nursing combined mode in the view of embeddedness. J Northwest Pop 2014; 35: 94-7.

15. Chen YG, Tang CH, Chen F, Luo X-C. Analysis of the construction of urban community Medicare and health service system for the old people in China. J Chongqing Technol Bus Univ (Social Science Edition) 2013; 30: $98-105$.

16. Liu N. Study on the horizontal integration and management modes among enterprises. J Comm Econ 2013; 14: 83-4.

17. Yan J. Study on the integration modes among enterprises in China. J Comm Econ 2013; 20: 94-5.

18. Andersen RM, Newman JF. Societal and individual determinants of medical care utilization in the United States. Milbank Mem Fund Q Health Soc 1973; 51: 95-124.

19. Aday LA, Andersen RM. A framework for the study of access to medical care. Health Serv Res 1974; 3: 208-20.

20. Aday LA, Andersen RM. Equity to access to medical care: a conceptual and empirical overview. Med Care 1981; 19: 4-27.

21. Andersen RM. Revisiting the behavioral model and access to medical care: does it matter? J Health Soc Behav 1995; 36: 1-10.

22. Fillenbaum GG, Burchett BM, Dan JD, Blazer G. Health service use and outcome: comparison of low charge, integrated, comprehensive services with usual health care. Aging Ment Health 2007; 11: 226-35.

23. Bleijenberg N, Drubbel I, Ten Dam VH, Numans ME, Schuurmans MJ, de Wit NJ. Proactive and integrated primary care for frail older people: design and methodological challenges of the Utrecht primary care PROactive frailty intervention trail (U-PROFIT). BMC Geriatr 2012; 12: 16-25.

24. Fabbricotti IN, Janse B, Looman WM, de Kuijper R, van Wijngaarden $\mathrm{JD}$, Reiffers A. Integrated care for frail elderly compared to usual care: a study protocol of a quasi-experiment on the effects on the frail elderly, their caregivers, health professionals and health care costs. BMC Geriatr 2013; 13: 31-43.

25. Spoorenberg SL, Uittenbroek RJ, Middel B, Kremer BP, Reijneveld SA, Wynia K. Embrace, a model for integrated elderly care: study protocol of a randomized controlled trial on the effectiveness regarding patient outcomes, service use, costs, and quality of care. BMC Geriatr 2013; 13: $62-73$.

26. Vedel I, De Stampa M, Bergman H, Ankri J, Cassou B, Mauriat C et al. A novel model of integrated care for the elderly: COPA, Coordination of Professional Care for the Elderly. Aging Clin Exp Res 2008; 21: 414-23.

27. Weaver FM, Hickey EC, Hughes SL, Parker V, Fortunato D, Rose et al. Providing all-inclusive care for frail elderly veterans: evaluation of three models of care. J Am Geriatr Soc 2008; 56: 345-53.

28. Low L-F, Yap M, Brodaty H. A systematic review of different models of home and community care services for older persons. BMC Health Serv Res 2011; 11: 93-108.

29. You EC, Dunt D, Doyle C, Hsueh A. Effects of case management in community aged care on client and carer outcomes: a systematic review of randomized trials and comparative observational studies. BMC Health Serv Res 2012; 12: 395-409.

30. King MA, Roberts MS. Multidisciplinary case conference reviews: improving outcomes on nursing home residents, carers and health professionals. Pharm World Sci 2001; 23: 41-5.

31. Applebaum R, Straker J, Mehdizadeh S, Warshaw G, Gothelf E. Using high-intensity care management to integrate acute and long-term care services: substitute for large scale system reform? Care Manag J 2002; 3: $113-9$.

32. Kane RA, Lum TY, Cutler LJ, Degenholtz HB, Yu TC. Resident outcomes in small-house nursing homes: a longitudinal evaluation of the initial green house program. J Am Geriatr Soc 2007; 55: 832-9.

33. van Bilsen PM, Hamers JP, Groot W, Spreeuwenberg C. The use of community-based social services by elderly people at risk of institutionalization: an evaluation. Health Policy 2008; 87: 287-97.

34. Fan WX, Li SH, Huang E. Study on management of medical-nursing combined mode for the elderly. J Trad Chinese Med Manag 2010; 18: $504-6$.

35. Yu WH, Lin D, Chen XL. Research status of medical-nursing combined long-term care. Chinese Nurs Manag 2013; 13: 91-3.

36. Gao XF, Yu WH. The relationship between ability of daily living, nursing time and nursing grading among elderly patients using treatment-care combined mode. Chinese Nurs Manag 2014; 14: 249-53.

37. Wu YX, Luo TJ, Luo WH. Practice and effect of implementing medical treatment and after treatment-nursing for elderly patients with chronic disease. Modern Hosp 2014; 14: 149-51.

38. Wolinsky FD, Coe RM, Miller DK, Prendergast JM, Creel MJ, Chavez MN. Health services utilization among the noninstitutionalized elderly. J Health Soc Behav 1983; 24: 325-37.

39. Dubuc N, Dubois M-F, Raîche M, Gueye NDR, Hébert R. Meeting the home-care needs of disabled older persons living in the community: does integrated services delivery make a difference? BMC Geriatr 2011; 11: $67-80$.

40. Salvador-Carulla L, Alvarez-Galvez J, Romero C, Gutiérrez-Colosía MR, Weber G, McDaid D et al. Evaluation of and integrated system for classification, assessment and comparison of service for long-term care in Europe: the eDESDE-LTC study. BMC Health Serv Res 2013; 13: 218-30.

41. Janse B, Huijsman R, de Kuyper RD, Fabbricotti IN. The effects of an integrated care intervention for the frail elderly on informal caregivers: a quasi-experimental study. BMC Geriatr 2014; 14: 58-70.

42. Hartgerink JM, Cramm JM, de Vos AJ, Bakker TJ, Steyerberg EW, Mackenbach JP et al. Situational awareness, relational coordination and integrated care delivery to hospitalized elderly in The Netherlands: a comparison between hospitals. BMC Geriatr 2014; 14: 3-10. 
43. de Stampa M, Vedel I, Trouvé H, Ankri J, Olivier SJ, Somme D. Multidisciplinary teams of case managers in the implementation of an innova- tive integrated services delivery for the elderly in France. BMC Health Serv Res 2014; 14: 159-70. 